\title{
Preliminary Data Call Report - Advanced Burner Reactor Start Up Fuel Fabrication Facility
}

S. T. Khericha

April 2007

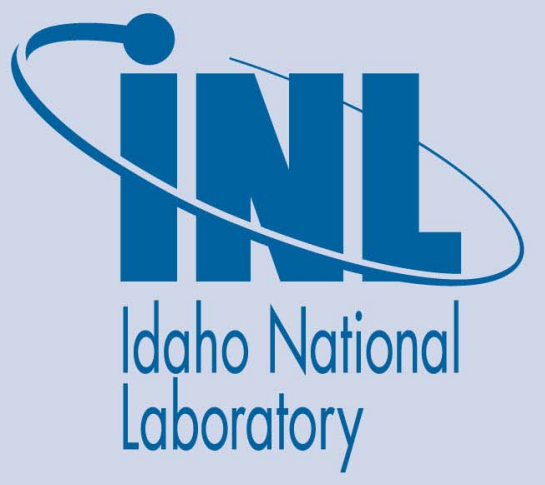

The INL is a U.S. Department of Energy National Laboratory operated by Battelle Energy Alliance 



\section{Preliminary Data Call Report - Advanced Burner Reactor Start Up Fuel Fabrication Facility}

S. T. Khericha

April 2007

Idaho National Laboratory

Idaho Falls, Idaho 83415

Prepared for the

U.S. Department of Energy

Office of Nuclear Energy

Under DOE Idaho Operations Office

Contract DE-AC07-05ID14517 
Preliminary Data Call Report Advanced Burner Reactor Start Up Fuel Fabrication Facility

INL/EXT-07-12567

April 2007

Approved by

D. L. Porter

D. L. Porter

$D C$ Crawford

D. C. Crawford

$4 \cdot 23.2007$

Date

Type 3rd persons name here

Date 


\begin{abstract}
The purpose of this report is to provide data for preparation of a NEPA Environmental Impact Statement in support the U. S. Department of Energy (DOE) Global Nuclear Energy Partnership (GNEP). One of the GNEP objectives is to reduce the inventory of long lived actinide from the light water reactor (LWR) spent fuel. The LWR spent fuel contains Plutonium (Pu) -239 and other transuranics (TRU) such as Americium-241. One of the options is to transmute or burn these actinides in fast neutron spectra as well as generate the electricity. A sodium-cooled Advanced Recycling Reactor (ARR) concept has been proposed to achieve this goal. However, fuel with relatively high TRU content has not been used in the fast reactor. To demonstrate the utilization of TRU fuel in a fast reactor, an Advanced Burner Reactor (ABR) prototype of ARR is proposed, which would necessarily be started up using weapons grade (WG) Pu fuel. The WG $\mathrm{Pu}$ is distinguished by relatively highest proportions of $\mathrm{Pu}-239$ and lesser amount of other actinides. The WG Pu will be used as the startup fuel along with TRU fuel in lead test assemblies. Because such fuel is not currently being produced in the US, a new facility (or new capability in an existing facility) is being considered for fabrication of WG Pu fuel for the ABR. This report is provided in response to 'Data Call' for the construction of startup fuel fabrication facility. It is anticipated that the facility will provide the startup fuel for 10-15 years and will take to 3 to 5 years to construct.
\end{abstract}





\section{CONTENTS}

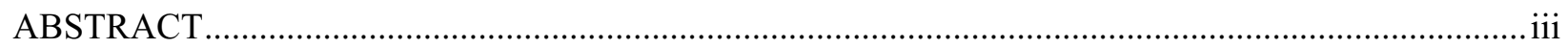

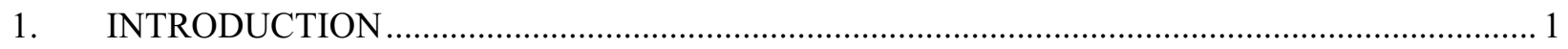

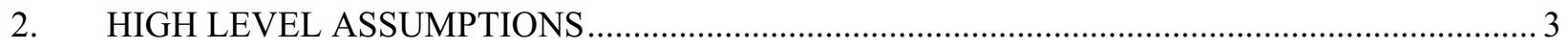

3. PRE-CONDITIONING OF WG PU FEEDSTOCK …...................................................... 6

4. METAL FUEL FABRICATION PROCESS AND EQUIPMENT ............................................ 10

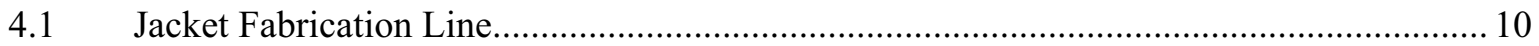

4.1.1 Cladding Tubes and Other Fuel Rod Hardware ........................................... 10

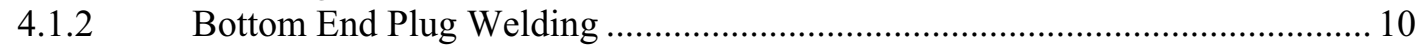

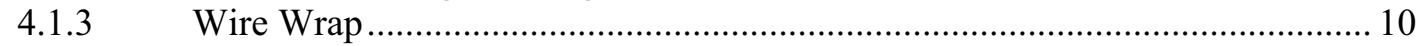

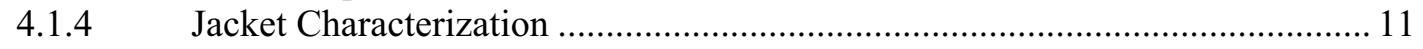

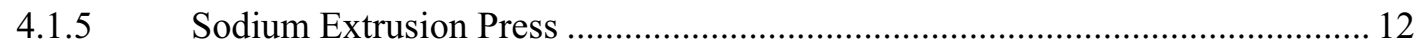

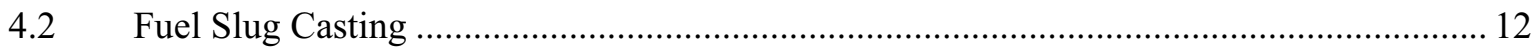

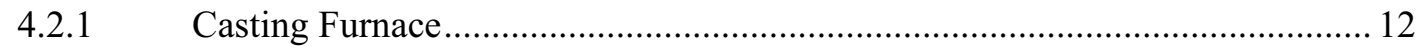

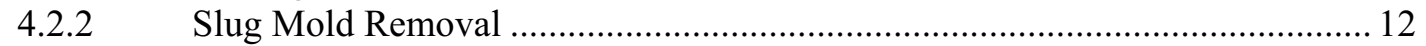

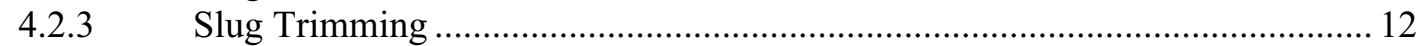

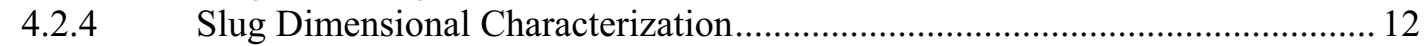

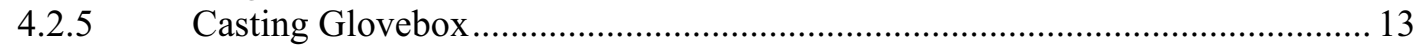

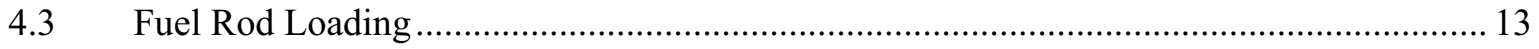

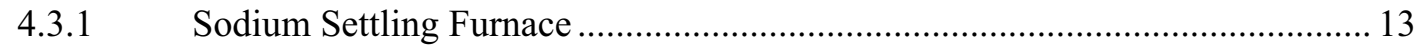

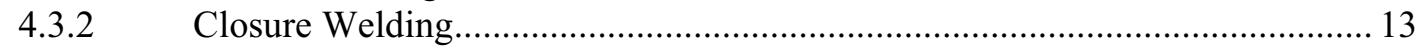

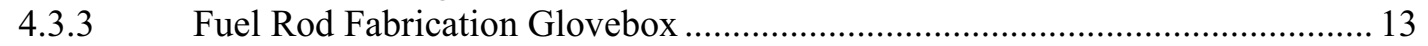

4.3.4 Fuel Rod Characterization and Quality Control.............................................. 13

5. MIXED OXIDE FUEL FABRICATION PROCESS AND EQUIPMENT .................................. 14

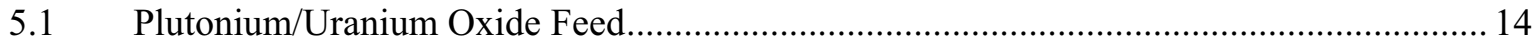

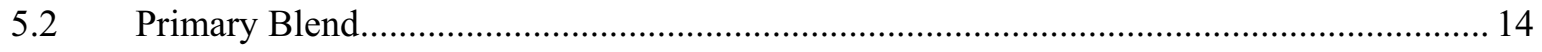

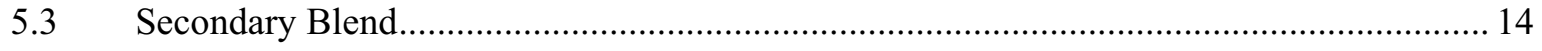

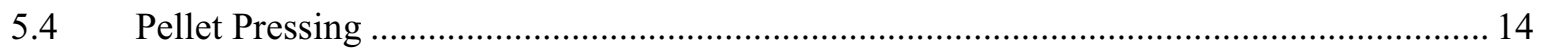

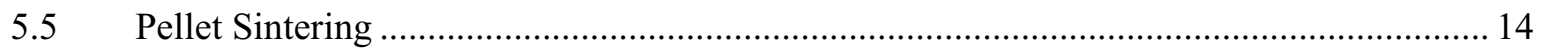

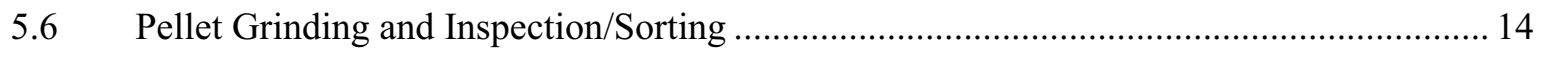

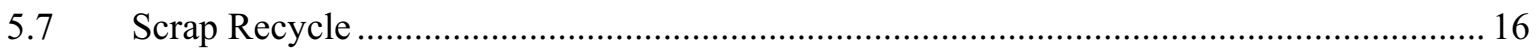




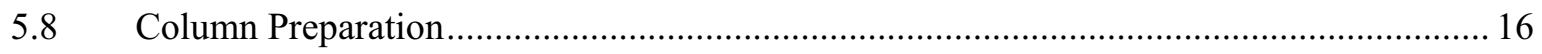

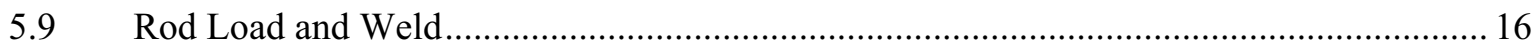

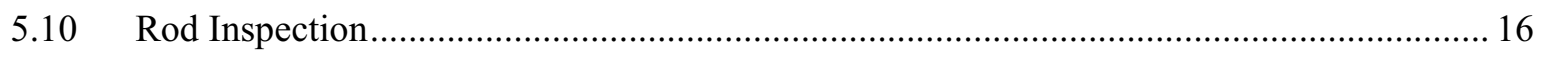

6. RESOURCE NEEDS FOR SFFF DURING CONSTRUCTION AND OPERATION ...................17

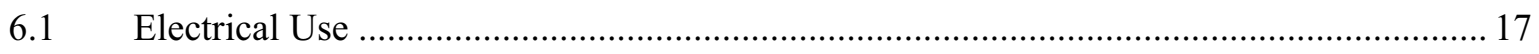

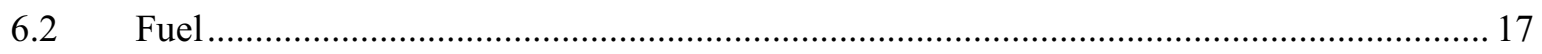

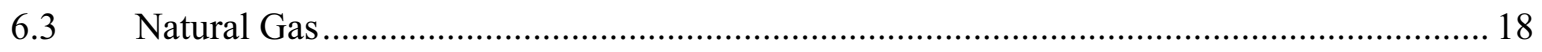

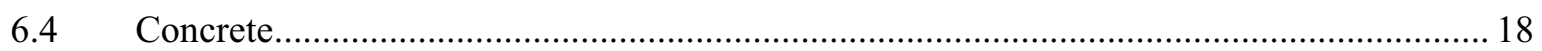

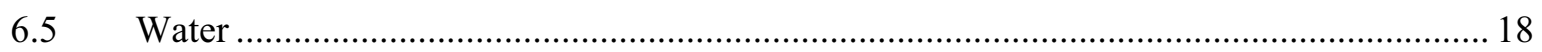

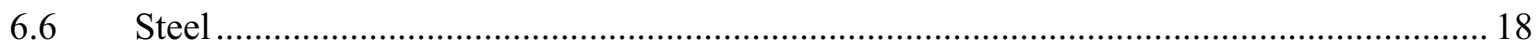

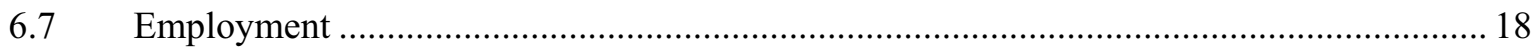

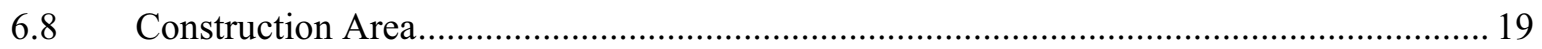

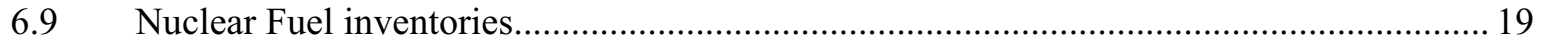

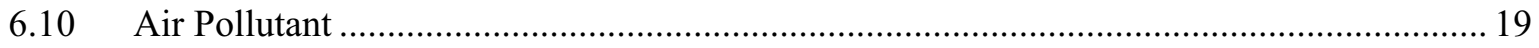

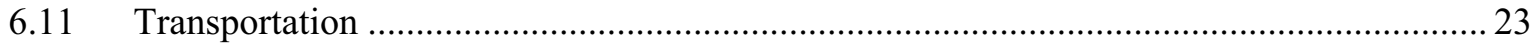

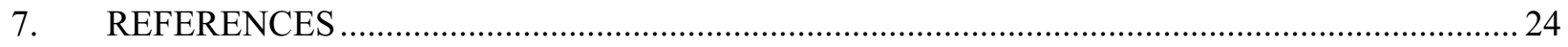




\section{FIGURES}

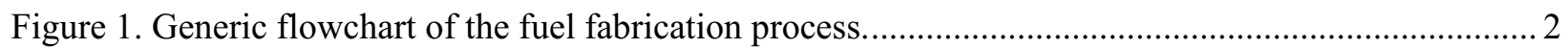

Figure 2. Simplified footprint of start up fuel fabrication facility ........................................................ 5

Figure 3. Simplified flow diagram of Ga removal aqueous process................................................... 7

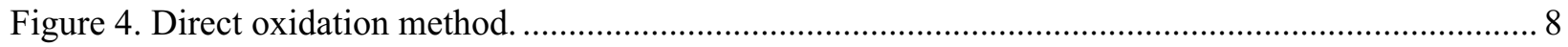

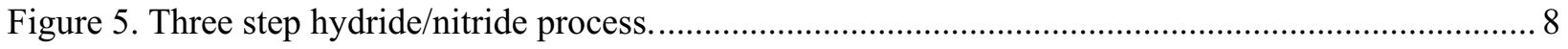

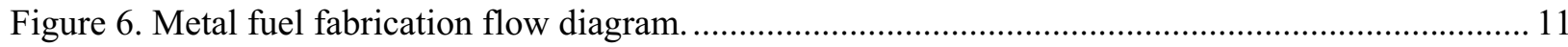

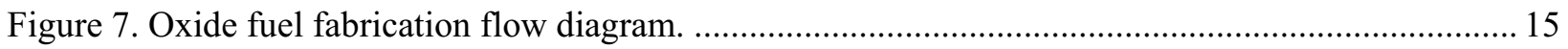

Figure 6. Plutonium inventory in metal fuel processing line............................................................... 19

Figure 7. Plutonium inventory in MOX fuel processing line................................................................ 19

\section{TABLES}

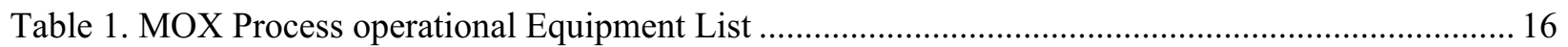

Table 2. Estimated Resource needs and waste generation during construction ....................................... 20

Table 3. Estimated Resource needs and waste generation during operation .......................................... 21

Table 4. List of annual chemical consumption for operations "............................................................. 22

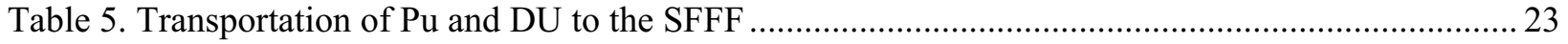





\section{Preliminary Data Call Report -- Advanced Burner Reactor Start Up Fuel Fabrication Facility}

\section{INTRODUCTION}

Data reported in this advanced burner reactor (ABR) start up fuel fabrication facility (SFFF) Data Call report represent the best efforts to provide reliable input to Tetra Tech, Inc. Every effort has been made to ensure the completeness of data as set forth in the Data Call. Detailed assumptions used in the development of the Initial Data Call Response are contained in this report. In general, it is preferred that the ABR SFFF will be located in one of the thirteen sites being evaluated in the ABR environmental impact statement (EIS). The SFFF will be housed in a new building constructed for that purpose, preferably co-located at the ABR site.

The facility is designed to fabricate plutonium-uranium mixed oxide (MOX) or metal fuel for GNEP ABR start up fuel at a rate of 1.4 metric tons (MT) Pu metal/yr to provide $2000 \mathrm{MW}_{\text {th }}$ ABR core fuel assemblies containing TRU for 10 to 15 years. Initial core loading is estimated to be $4 \mathrm{MT} \mathrm{Pu}$ isotopes. Over the life of the facility 15 to $21 \mathrm{MT}$ Pu isotopes will be processed. The facility will be licensable by the Nuclear Regulatory Commission (NRC), and will comply with applicable federal, state and local environmental, health and safety requirements.

The facility is envisioned to consist of plutonium feed preparation (Ga removal) and couple of assembly lines made up of several inter-connected glove boxes and storage at each step until the fuel pins are assembled. Primary purpose of the glove boxes is to prevent spread of airborne contamination and provide appropriate inert environment as needed. Fuel pins will be transferred and stored in the fuel assembly area. The feed stock storage (vaults), pre-processing steps, fuel fabrication processing, post fuel processing inspections of slugs/pellets, physical and chemical analyses, slugs/pellets loading in pin, and fuel bundle assembly will take place in one building. The analytical labs and personnel offices will be in the same building.

The SFFF facility will receive uranium and plutonium oxide/metal feedstocks for processing into MOX/metal fuel. Sanzo (2006) provides an initial assessment of the plutonium that is potentially available for use in an ABR as part of the Global Nuclear Energy Partnership (GNEP). There is no adequate supply of fuel grade (FG) Pu available to be used in ABR (Sanzo, 2006) as start up fuel. Therefore, it is anticipated that existing weapon grade (WG) Pu will be used in the start up fuel. The WG $\mathrm{Pu}$ will need to be processed to remove gallium to the desired level. In addition to gallium, the major differences between grades of plutonium are the concentration of various $\mathrm{Pu}$ isotopes and other transuranics, such as americium. WG Pu contains the highest concentration of Pu-239, followed by FG Pu and finally reactor grade (RG) $\mathrm{Pu}$. The $\mathrm{RG} \mathrm{Pu}$ contains higher concentration of other nuclides and therefore requires the greatest emphasis on worker protection from radiation fields and contamination control, WG requires the least. One of the GNEP goal is to reduce the actinide inventory from the RG Pu.

A generic flow chart of the start up fuel fabrication process is presented in Figure 1. The entire facility will be available for inspection by the International Atomic Energy Agency (IAEA). Based on engineering judgment and recent experiences in constructing nonreactor nuclear facilities, a 3 to $5 \mathrm{yr}$ construction period is assumed for a new facility. A 2-yr startup period (1-yr for cold startup and 1-yr for hot startup) is assumed. 


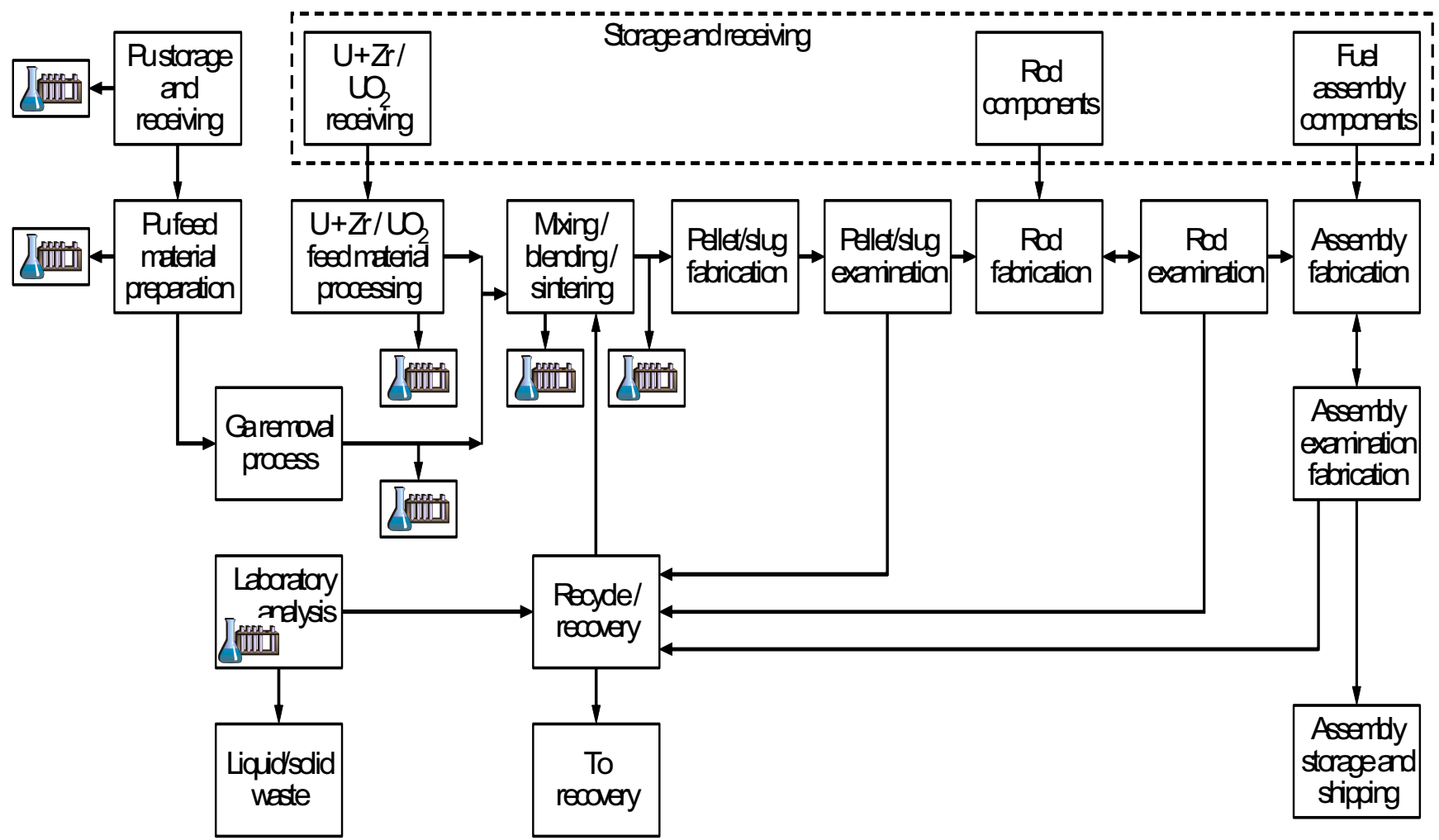

Figure 1. Generic flowchart of the fuel fabrication process. 


\section{HIGH LEVEL ASSUMPTIONS}

For analysis purposes, a generic pre-conceptual layout of a 76,000 $\mathrm{ft}^{2}(48,000$ main floor $+26,000$ basement) facility, as shown in Figure 2, is used to provide a common basis for comparison of each candidate site. This generic layout is based on existing designs and MOX/metal fuel fabrication experience and serves as a typical facility in which all the major functions appropriate to $\mathrm{MOX} / \mathrm{metal}$ fuel fabrication facilities are represented. A more detailed design of the actual ABR SFFF will be conducted after DOE has selected the consortium of industry groups to design, construct, and operate the facility. Additional environmental analyses will be performed, as appropriate, to support the facility licensing process.

Key assumptions used in development of preliminary 'Data Call' for advanced burner reactor (ABR) start up fuel fabrication facility (SFFF):

- $\quad$ The facility is Safeguard and Security (S\&S) category 1.

- It is preferable that the SFFF be co-located at one of thirteen sites being considered in the ABR EIS.

- $\quad$ The facility will be licensable by the Nuclear Regulatory Commission (NRC), and will comply with applicable federal, state and local environmental, health and safety requirements.

- $\quad \mathrm{Pu}$ is assumed to be WG feedstock and will require upfront processing to remove gallium.

- Initial fuel loading is assumed to be total of 18 and 13.9 MT of HM for metal and oxide fuel, respectively. Pu (TRU) loading is estimated to be 4 MT for both types of fuel (Kim 2006).

- The core is composed of 331 fuel assemblies; each assembly contains 397 pins.

- $\quad$ Metal start up fuel compositions are 70/20/10:DU/Pu (WG)/Zr. MOX start up fuel compositions are 63/25/12:DU/Pu (WG)/Oxygen.

- $\quad$ Based on replacement of one-third of fuel in the core per year, an annual throughput of minimum of 110 assemblies (minimum) is required. For the SFFF, total throughput is assumed to $10 \%$ more, i.e., total of 120 assemblies.

- $\quad$ Fuel fabrication plant recycle, scrap material and waste are based on FCF and FMF experiences.

- In the case of metal fuel, total $67 \%$ of feed is assumed to be recycled, $4 \%$ goes to recovery and $2 \%$ is waste to be immobilized.

- In the case of oxide fuel, total $33 \%$ of feed is assumed to be recycled, $4 \%$ goes to recovery and less than $1 \%$ is waste to be immobilized.

- It is assumed that no more than $4 \mathrm{~kg}$ of $\mathrm{Pu}$ will be processed per batch due to criticality concern.

- The facility will consist of 2 assembly lines (multiple internally-connected glove boxes in an assembly line); with each line capable of producing $\sim 65$ assemblies/year. 
- $\quad$ Since $\mathrm{Pu}$ is WG feedstock, the minimum shielding requirement will be needed in the processing line.

- $\quad$ Energy requirements to process the oxide or metal fuel is assumed to be the same.

- $\quad$ The facility excess capacity is designed to be $20 \%$ higher than the normal yearly throughput requirement.

- $\quad$ Fuel hardware other than fuel pellets (MOX) or slugs (metal) such as caps, springs, tubes, etc., are purchased from the off-site qualified suppliers.

- $\quad$ Maximum total facility maximum Pu metal inventory, in oxide or metal form, consist of 65 assemblies (50\% of annual output), 6 months of feed stock, plus material that is being processed in the assembly lines assumed to be very small compared to the total inventory.

- $\quad$ Periodically, the waste will be collected from each assembly line and laboratory, recorded and packed in approved shipping containers (55-gallon drums) on an as-needed basis. The packed containers will be stored at site until shipped to appropriate waste storage depository.

- Other required infrastructure elements such as fire and emergency response, security, transportation, environmental monitoring and other auxiliary facilities are shared with the ABR facility and assumed to be adequate.

References are provided in the appropriate sections. In some cases, referenced data were not available and the values given are estimates based on best engineering judgment. References related to recent European MOX experience, Data Call for Pantex, and SRS MOX fuel lead assembly fabrication facilities, the INL Fuel Conditioning Facility (FCF) and Fuel Manufacturing Facility (FMF) experiences were reviewed and have been used where applicable. However, much of the detailed information concerning operating European facilities is proprietary. 


\begin{tabular}{|c|c|c|c|}
\hline & $\begin{array}{c}\text { Support Lab } \\
\text { and Offices }\end{array}$ & \\
\cline { 2 - 2 } $\begin{array}{c}\text { Receiving, } \\
\text { Storage } \\
\text { and Feed } \\
\text { Preparation }\end{array}$ & $\begin{array}{c}\text { Pu } \\
\text { Conditioning }\end{array}$ & MOX Fuel Fabrication & $\begin{array}{c}\text { Waste } \\
\text { Prepara- } \\
\text { tion and } \\
\text { storage }\end{array}$ \\
\cline { 2 - 4 } & $\begin{array}{c}\text { Support Lab } \\
\text { and Offices }\end{array}$ & Mupport \\
\cline { 2 - 5 } & & Offices \\
\hline
\end{tabular}

Simplified Footprint of SFFF First Floor Level (150' x 320')

\begin{tabular}{|c|c|c|c|}
\hline \multirow{2}{*}{$\begin{array}{l}\text { Receiving, } \\
\text { Storage } \\
\text { and Feed } \\
\text { Preparation }\end{array}$} & $\begin{array}{c}\mathrm{Pu} \\
\text { Conditioning }\end{array}$ & MOX Fuel Fabrication & $\begin{array}{c}\text { Waste } \\
\text { Process- } \\
\text { ing and } \\
\text { Storage }\end{array}$ \\
\hline & \multicolumn{3}{|c|}{ Support Offices } \\
\hline
\end{tabular}

Simplified Footprint of SFFF Basement Level (100' x 280')

Figure 2. Simplified footprint of start up fuel fabrication facility 


\section{PRE-CONDITIONING OF WG PU FEEDSTOCK}

Gallium in concentrations of up to 1 percent were used as an alloying element in WG plutonium pits. Gallium at such concentrations presents various issues for MOX fuel fabrication and use. Therefore, its concentration must be greatly reduced if the MOX option for plutonium disposition is pursued. At present, the impact of gallium in metallic fuel fabrication, irradiation in fast reactor and high burnup ( $>50$ GWD/MT in MOX) is not known.

MOX fuel is essentially a ceramic material, prepared by sintering oxides of uranium and plutonium, which are initially both in the form of fine powders. At high concentrations, gallium affects the sintering behavior of the ceramic. In addition, there may be issues with using MOX fuel with excessive gallium concentration as a reactor fuel. While gallium is neutral from neutronic perspective, and would not interfere with the chain reaction, gallium metal chemically attacks zirconium clad (Wilson 1997). The presence of excessive gallium in MOX fuel raises operational and disposal safety concerns. There may also be other problems with the presence of large amounts of gallium, but it has not yet been established whether these are significant concerns. For instance, gallium may affect fission product migration in spent fuel.

There are currently two processes used to remove gallium: an aqueous process and a dry process. The aqueous process is a fully developed technology for gallium removal and plutonium oxide production, which results in the generation of large quantities of liquid radioactive wastes. For this reason, it would be highly desirable to avoid using the aqueous process and instead use the dry processes being developed at the Los Alamos and Livermore National Laboratories (Kolman 2000, Bluhm 2004). However, this document includes the resource needs and waste stream based on aqueous process.

The aqueous process is based on dissolution, purification via solvent extraction or ion exchange, and solidification of purified Pu product (ORNL 1998, DeMuth 1997).

The configuration used for this process includes:

- dissolution of $\mathrm{Pu}$ in nitric acid/hydrogen-fluoride or Pu-oxide in nitric acid (electrolytic dissolution with silver as a catalyst)

- $\quad$ purification via solvent extraction or ion exchange

- $\quad$ plutonium (IV) oxalate precipitation at approximately 65 degrees Celsius to help ensure proper oxide-powder morphology and to complete the purification efforts;

- $\quad$ calcination in a furnace using rigorously blending in a blender.

A generic aqueous process flow diagram is shown in Figure 3.

Two approaches for converting plutonium pits into oxide were investigated at Los Alamos and Lawrence Livermore National Laboratories (Kolman 2000). One approach, as shown in Figure 4, is that plutonium metal is converted directly into oxide at $600^{\circ} \mathrm{C}$. Another process, as shown in Figure 5, would convert plutonium metal into a hydride, the hydride into a nitride (PuN), and then to an oxide. As compared to the three step process, the direct metal oxidation method produces a more coarse powder having less surface area per gram. After either process, gallium is also in oxide form, $\mathrm{Ga}_{2} \mathrm{O}_{3}$. (To remove hydrogen and provide a metal product, the hydride is simply heated to drive off hydrogen, leaving a plutonium metal ingot.) These approaches are part of the Advanced Recovery and Integrated Extraction System (ARIES) process for pit disassembly and conversion. 


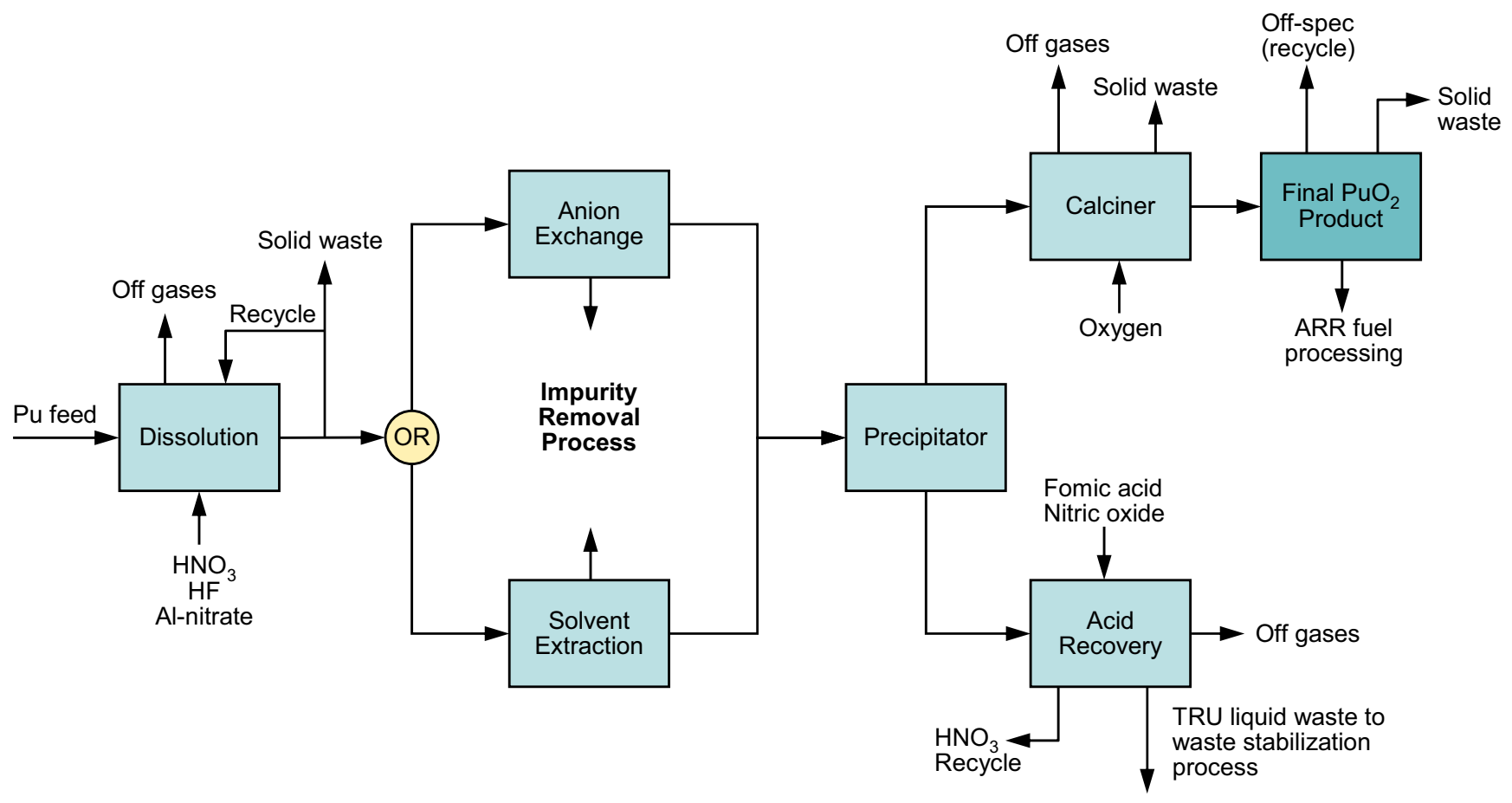

Figure 3. Simplified flow diagram of Ga removal aqueous process. 
In each case, the gallium would be removed after plutonium oxide has been made. The gallium is driven out by reduction and conversion to a sub-oxide form $\left(\mathrm{Ga}_{2} \mathrm{O}\right)$ in an atmosphere of argon with 6 percent hydrogen (Kolman 2000). The sub-oxide of gallium rapidly volatilizes from the plutoniumgallium mix at $1200^{\circ} \mathrm{C}$. This process also known as thermally-induced gallium removal (TIGR), which has been tested at the laboratory scale, gets gallium down from about 1 percent to 200 parts per million. Current thinking in the MOX fuel fabrication industry in Europe is that this level of gallium content is probably acceptable because it is comparable to or beneath the level of other contaminants, now present in MOX fuel used in European reactors, that also might interact with cladding.

In U.S., the MOX fuel (1-5 ppm Ga) manufactured by LANL using TIGR process was irradiated in the Advanced Test Reactor (ATR) at Idaho National Laboratory at various burnup levels, from 8 to 52 $\mathrm{GWd} / \mathrm{MT}(<1$ to $>5$ atom \%). It is concluded that any migration of gallium from fuel to cladding is insignificant and presents no credible threat to the cladding integrity (Hodge 2006 and Ott 2005).

However, the ATR is a thermal reactor and fuel burnup in the ABR is expected to exceed those to which these tests have been subjected. In mid-1994, five fuel elements (U-19.8\%Pu-10 Zr,-0.2 Ga) made from WG Pu $(1 \% \mathrm{Ga})$ were irradiated in EBR-II before it was shut down. These elements achieved a peak burnup of only 1.5 atom $\%$. To date, no post-irradiation examination has been done on these elements. At present, no significant amount of data or experience exist on irradiation of high Pu-enriched MOX or metallic fuel manufactured from WG feedstock, where gallium is present as impurity, in fast reactor environment

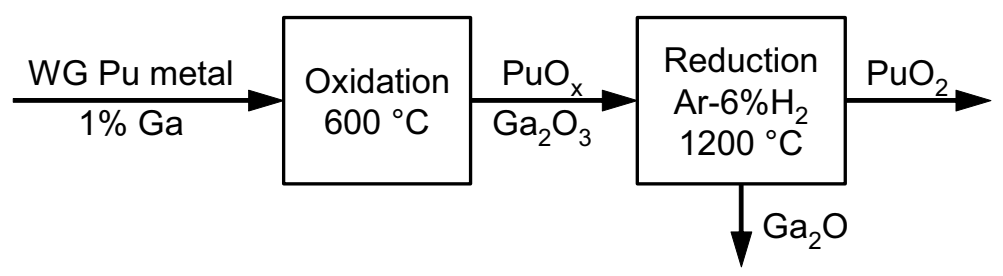

Figure 4. Direct oxidation method.

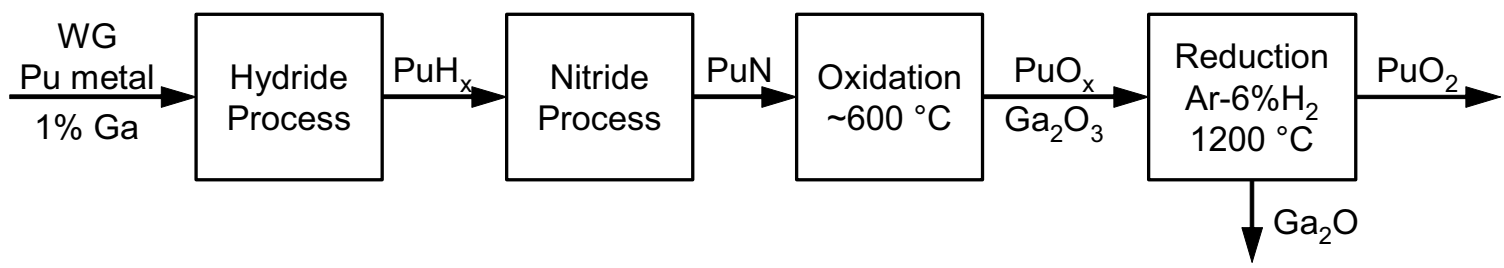

Figure 5. Three step hydride/nitride process.

The hydride process for converting plutonium to a metal ingot is now standard in plutonium processing at Los Alamos and Livermore. However, the conversion process to oxide and the gallium removal processes are not yet fully developed. The main problem with oxide conversion is managing the release of heat in converting the hydride to oxide, while maintaining the oxidation rate high enough to provide good production throughput. If the hydride becomes too hot, some hydride will be converted to plutonium metal, forming "clinkers." Similarly, in conversion of the nitride to oxide, overheating can cause formation of large, hard clumps of oxide. Engineering is underway to remove the excess heat efficiently, allowing shorter oxidation times and greater throughput. 
Since plutonium pits do not all have the same concentration of gallium, the sintering process parameters would have to be adjusted as the gallium concentration changed (undesirable in an industrialscale operation) unless the gallium was reduced to an acceptable level prior to fabrication.

Note that at present, no significant amount of data or experience exist on irradiation of high $\mathrm{Pu}$ enriched MOX or metallic fuel manufactured from WG feedstock, where gallium is present as impurity, in fast reactor environment. 


\section{METAL FUEL FABRICATION PROCESS AND EQUIPMENT}

The metal fuel fabrication process involves three main parts: jacket fabrication, fuel slug casting, and fuel rod loading. Jacket hardware can be commercially procured, then inspected at the fabrication facility. Jacket fabrication proceeds with a bottom endplug being welded to the jacket, the spacer wire wrap attached, and sodium loaded into the inspected jacket. After sodium loading, the jackets are dimensionally characterized then proceed to fuel rod fabrication. Fuel slugs are injection cast using an induction-heated furnace and cut to length in an argon atmosphere glove box. The fuel rods are then loaded with the fuel, settled into the bond sodium, and sealwelded in a clean section of an argon atmosphere glove box and then removed for bonding. Figure 6 shows the main process flow steps for fuel slug casting and fuel rod loading.

The glove box atmosphere for various fabrication steps is a purified inert atmosphere to prevent pyrophoric reaction, but more practically it helps maintain purity of the sodium and fuel inside the fuel rod, which might otherwise decrease with oxygen or moisture content due to reaction products on the surface of the sodium material or fuel slugs. The impact of additional oxygen impurities on fuel performance is not fully evaluated, and subsequent work may suggest that impurity tolerances in the fabrication atmosphere can be relaxed.

The following describes the equipment required for the fabrication process:

\subsection{Jacket Fabrication Line}

\subsubsection{Cladding Tubes and Other Fuel Rod Hardware}

Fuel rod hardware will be commercially procured, as may the assembly of the components into fuel rod jackets and end plugs. The operation at the SFFF may only require that the top end plug be welded to the jacket to seal in the fuel, and perhaps attach a wire wrap to the exterior of the cladding. Experimental

Breeder Reactor II (EBR-II) experience has shown this to be an acceptable manner to obtain material. All cladding tubes and fuel jackets will be inspected to verify conformance to the specification. It is anticipated that the specifications will be similar to those used previously for EBR-II cladding procurement. Other hardware or materials to be used for hardware fabrication on-site will follow a similar process.

\subsubsection{Bottom End Plug Welding}

The number and quality of bottom jacket welds necessitates an automated or semi-automated welding process be used to obtain a sufficiently low rejection rate. Orbital Gas Tungsten Arc Welding (GTAW) will be used. This method of welding has been used for fuel fabrication previously and is widely used in the pipe and tube welding industry. This system can be commercially procured and then qualified for use on these welds.

\subsubsection{Wire Wrap}

The ABR design uses a wire wrap as employed in previous fast reactor fuel fabrication campaigns. Little developmental work will be required because a system has been built and used in the past. A similar system will be assembled to weld the bottom of the wire in place, wrap the wire around the jacket, then weld the top wire end in place. 


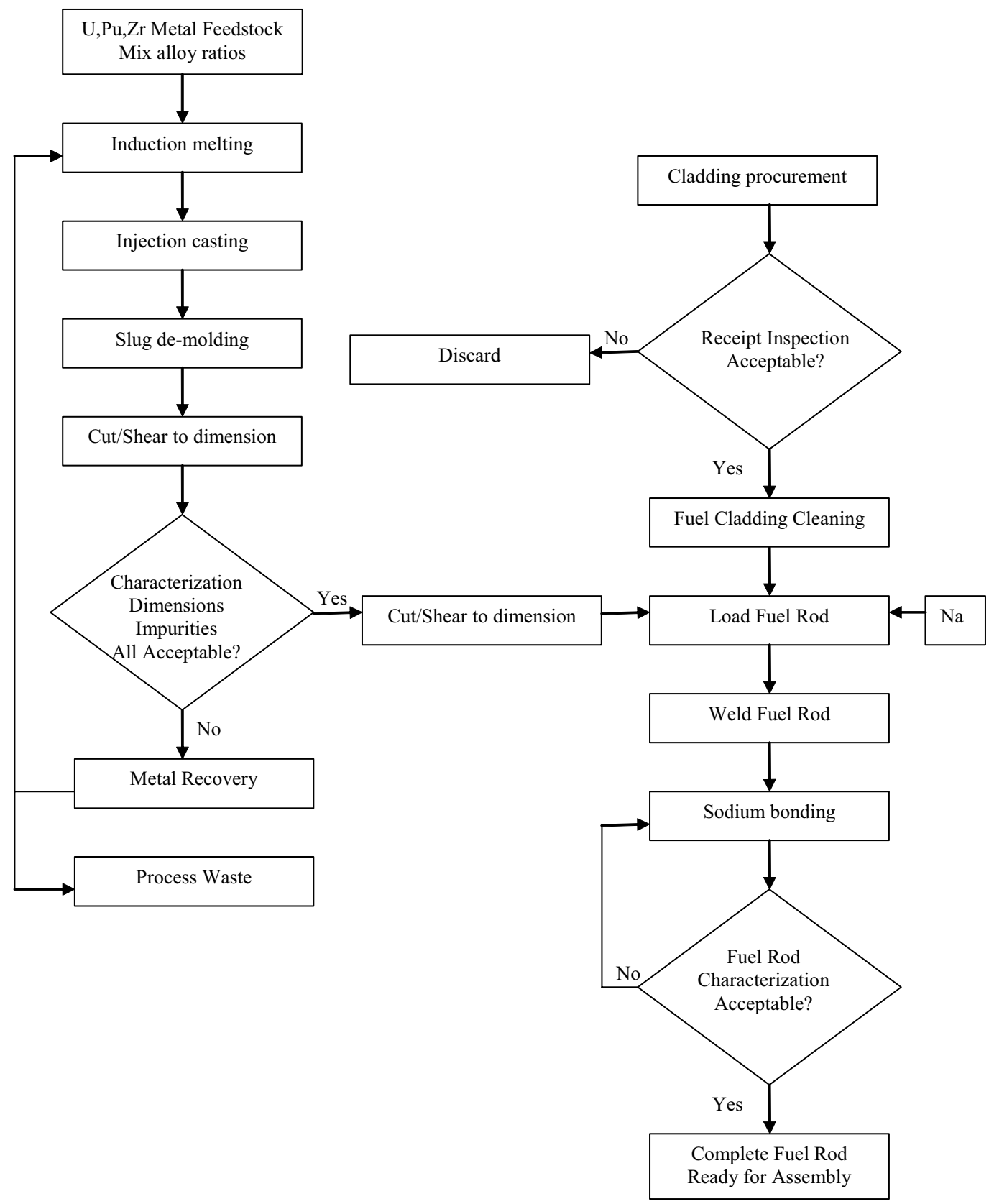

Figure 6. Metal fuel fabrication flow diagram.

\subsubsection{Jacket Characterization}

The completed jackets will be dimensionally characterized. The number of fuel rods to be fabricated makes desirable use of semi-automated instruments such as laser micrometers, profilometers, air gauges, etc. End-plug welds will undergo radiographic inspection as well as leak testing. 


\subsubsection{Sodium Extrusion Press}

Metal fuel swells upon irradiation, therefore a gap between the fuel and cladding to accommodate this swelling is built into the fuel rod. In order to increase heat transfer from the fuel to the cladding, this gap must be filled with a substance with a high thermal conductivity. Because metal fuel is compatible with sodium coolant in fast reactors, it was decided that the best heat conduction medium was sodium. It is critical to keep jacket welding surfaces free of sodium, therefore sodium needs to be placed in the jacket in solid form before the slugs are loaded. Past experience has shown it is easiest to do this by cold extruding a sodium wire using a sodium extrusion press. The wire should have a diameter small enough so that it will easily drop into the jacket. Sodium is easily deformed at room temperature and therefore the press should be easily fabricated. Drawings of past presses exist and can be used to assemble additional presses.Sodium Loading Glovebox

Sodium is a reactive alkali metal that therefore must be handled in an inert atmosphere glovebox. Operating parameters of the glovebox should be set to maintain a moisture and oxygencontent of $<50$ $\mathrm{ppm}$. However, it is not necessary to maintain levels lower than $25 \mathrm{ppm}$ because too pure an atmosphere increases the difficulty in working with the sodium because of stickiness.

\subsection{Fuel Slug Casting}

\subsubsection{Casting Furnace}

The casting furnace will need to be constructed for plutonium containment and of a suitable size to cast at least tens of slugs per batch. The furnace will be capable of homogenizing the alloy melt and injection casting in one operation. The furnace will be of the induction type and will heat the melt under vacuum to facilitate injection casting as well as to preclude any reactions with the atmosphere. After sufficient heating and homogenization, quartz glass molds will be lowered into the melt, and the furnace will be pressurized to force the melt into the molds. This furnace will be modeled after existing casting furnace designs that were used in the FMF to produce fuel for EB-II.

\subsubsection{Slug Mold Removal}

Initially, single-use quartz glass molds will be used for injection casting. Mold removal will be accomplished by thoroughly breaking the molds and removing the slugs. After slug removal, the glass shards and residual fuel scrap will be separated by physically separating larger pieces and electromagnetically separating fines.

\subsubsection{Slug Trimming}

$\mathrm{U}-\mathrm{Pu}-\mathrm{Zr}$ alloy is a brittle alloy, and fuel slugs can be trimmed in a number of ways. Traditional shearing, sawing, or striking with a hard chisel all have been shown to produce acceptable results. Slug trimmings as well as sacrificial slugs will be used for alloy microstructural and chemical characterization. Trimmings not needed for characterization will be recycled back into the casting process.

\subsubsection{Slug Dimensional Characterization}

Because this work will be done in a glovebox with tens of slugs per batch, it is preferred to use as many semi-automated quality control instruments as possible. Such instrumentation will include laser micrometers, profilometers, air gauges, etc. All slugs will be individually weighed. All instrument outputs will be automatically recorded and tracked using computer software. This will not only diminish operator fatigue and error but also be amenable to data trending. 


\subsubsection{Casting Glovebox}

The casting glovebox will be an inert atmosphere glovebox designed and approved for plutonium use. All pressure control systems will be at least tertiary. Oxygen and moisture impurities must be maintained to $<50 \mathrm{ppm}$ levels, and other impurities such as nitrogen should also be monitored if feasible. The glovebox should be large enough for crucible loading, casting, trimming, quality control, crucible coating, and casting alloy heel size reduction for recycle. The metal fuel is a reactive metal and therefore will react with oxygen and oxidize, and fine powders which may be produced through the demolding and shearing process are pyrophoric. This is also the case with the oxide fuels; the (U,Pu) $\mathrm{O}_{2}$ will rapidly oxidize to a higher oxide if left in an oxygen-rich atmosphere. In the case of the casting furnace or the sintering furnace, both will need atmospheric control, since the rate of oxidation, and hence heat production increases at higher temperatures.

\subsection{Fuel Rod Loading}

\subsubsection{Sodium Settling Furnace}

Bond sodium is settled into the fuel/cladding gap by heating the loaded fuel pin to approximately $150^{\circ} \mathrm{C}$ and holding for 15 minutes. The furnace should be a multi-zone resistively heated furnace long enough to cover the fuel and plenum zone. This furnace will be installed in the fuel rod fabrication glovebox and therefore must be designed to run in inert atmospheres of argon, helium, or a mixture of argon and helium.

\subsubsection{Closure Welding}

The closure weld, at the upper end plug, has the same requirements as the bottom jacket weld. The system should be at a minimum semi-automatic and produce reproducible high-quality welds. Two systems are currently under consideration: a capacitance discharge (CD) type or an orbital GTAW. Both have been shown to be feasible through past fabrication experience, and both meet the requirements. Earlier EBR-II fuel fabrication experience relied on CD welding, The CD system uses simpler machinery with fewer parts than orbital welding, which leads to easier maintenance. However, orbital welding is used throughout the welding industry, and many standard systems which could be used inside a glovebox can be purchased "off the shelf".

\subsubsection{Fuel Rod Fabrication Glovebox}

Fuel loading of the jacket, slug settling, and closure welding will take place in the fuel rod fabrication glovebox. This glovebox will be a purified inert atmosphere glovebox capable of running in argon, helium, or a mixture of the two. The box should have two separate bays separated by a bulkhead. Fuel slugs will be exposed on one side and loaded into the jacket through a feed-through in the other side. This will keep the external surfaces of the rods free of contamination.

\subsubsection{Fuel Rod Characterization and Quality Control}

The completed rods will be dimensionally characterized. Semi-automated instruments, such as laser micrometers and profilometers will be used because of numbers of rods to be fabricated. All welds will undergo radiographic inspection as well as leak testing. 


\section{MIXED OXIDE FUEL FABRICATION PROCESS AND EQUIPMENT}

MOX fuel rod fabrication process is derived from the processes used to fabricate fuel for light water (thermal) reactor in Europe. The process for fabrication of MOX fuel rods for fast reactors, such as the ABR, is expected to be similar. Anticipated differences are discussed in the descriptions below. The general MOX fuel rod fabrication process is illustrated in Figure 7, and more detailed descriptions are provided following the figure. This description is not meant to be all-inclusive, but is representative of the scope of work associated with the fabrication processes.

\subsection{Plutonium/Uranium Oxide Feed}

Plutonium and uranium oxide feed material (see Sec. 8 for discussion of potential feed stocks) is required to meet rigorous specifications for isotopic vector, impurity content, particle size distribution, and residual moisture. The feedstock can include scrap material from previous runs, which is considered to improve the final product.

\subsection{Primary Blend}

In the primary blend step, the plutonium oxide, uranium oxide, and scrap feed materials are initially blended. The feedstock is poured into a blending jar, and milling media may be added to enhance particle size requirements. During this operation, binders and pore formers may also be added. The primary blend step typically produces $20-30 \mathrm{wt} \% \mathrm{PuO}_{2}$ blended powder that is intimately mixed, with a fine particle size.

\subsection{Secondary Blend}

In the secondary blend operation, another blender jar is filled with primary blend and additional uranium oxide, then run on a Turbula ${ }^{\circledR}$ blender. The secondary blend step may not be required for the fast reactor MOX fuel with $20-30 \%$ plutonium.

\subsection{Pellet Pressing}

The blend jar is connected to the pellet press sieve, and the blend is sieved and transferred to the press feed hopper. Pellets are pressed using a hydraulic press that can press one or more pellets simultaneously. The pellets are then placed on the sintering boats and stored.

\subsection{Pellet Sintering}

The sintering boats containing green pellets are removed from the green pellet storage glovebox and are loaded into the sintering furnace. The furnace operates as a batch process at a specified rate, resulting in a time-temperature sintering profile that meets specified requirements.

\subsection{Pellet Grinding and Inspection/Sorting}

The pellets are placed in a grinder feed hopper and processed through a centerless grinder to obtain the required diameter. Pellet diameter is confirmed during the grinding process using a laser micrometer. These pellets are further inspected according to the specification and sorted, with scrap pellets segregated. 


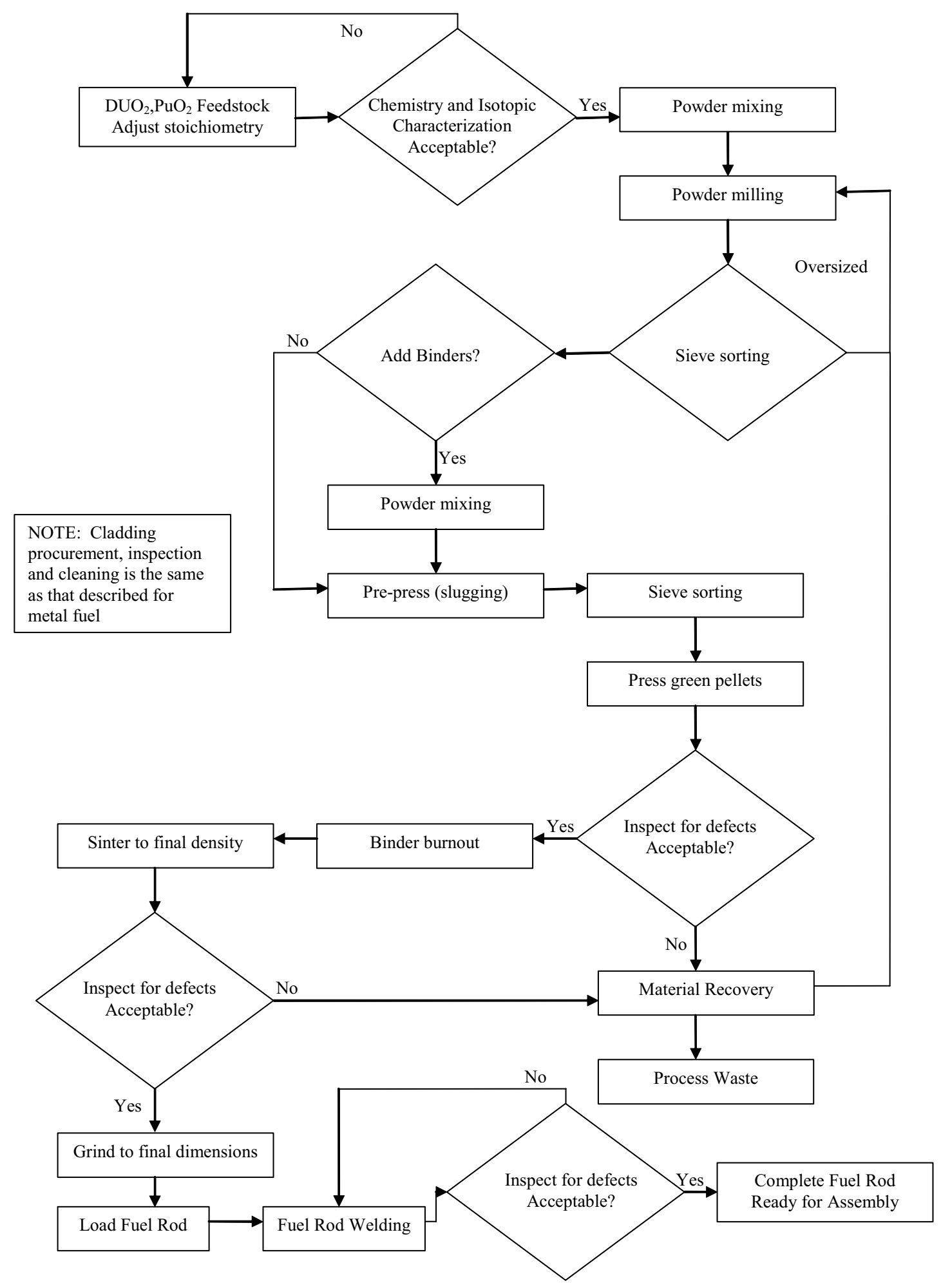

Figure 7. Oxide fuel fabrication flow diagram. 


\section{$\left(\mathrm{DUO}_{2}=\right.$ Depleted Uranium Oxide; 0.2 to 0.3 enrichment $)$}

\subsection{Scrap Recycle}

Rejected pellets are collected in a crusher box. After collecting a sufficient quantity, a jaw crusher reduces them to a suitable particle size. This material can become part of the feed for future fuel pellets.

\subsection{Column Preparation}

The sorted pellets are set for the column length needed for one fuel rod. The fuel rod subassembly (fuel rod cladding with its bottom end cap pre-welded into place) is slid through a hood enclosure at the end of the fuel rod fabrication glovebox and into the purge chamber.

\subsection{Rod Load and Weld}

The fuel pellet column is loaded into the fuel rod cladding. After decontaminating the rod, spring and end cap are installed. The assembled fuel rod is slid into the welding compartment, where the end cap is permanently welded into place using a rotary TIG (Tungsten Inert Gas) welder.

\subsection{Rod Inspection}

Following seal weld inspection and verification that decontamination requirements are met, the fuel rod assembly is slid back through the welding compartment and out of the hood enclosure. The fuel rod is then inspected by X-ray techniques for welds and gamma scanned to verify pellet plutonium concentration.

A wire wrap is not added to the oxide rods until assembly fabrication, as discussed in Sec. 3.5. Table 1 lists by process the major pieces of equipment needed for MOX fuel production.

Table 1. MOX Process operational Equipment List

\begin{tabular}{|c|c|c|}
\hline Process & Equipment & Comment \\
\hline Batching & Balance & $\begin{array}{l}\text { Needed throughput processing line for } \\
\text { nuclear material accountability. }\end{array}$ \\
\hline Blending & Blend Jar & Needed for blending and storage. \\
\hline Milling & Attrition Mill & Continuous feed. \\
\hline Pressing & Automatic Hydraulic Press & Multiple die set for throughput. \\
\hline Sintering & Resistance Furnace & Batch furnace. \\
\hline Grinding & Centerless Grinder & Automatic feed. \\
\hline Pin Welding & Orbital TIG Welder & Identical cold and hot setup. \\
\hline $\mathrm{O} / \mathrm{M}$ Analysis & Furnace w/hygrometer & In-line measurement capability. \\
\hline Dimensions & Digital Indicator, Laser Micrometer & Length, radius, chamfer, dish \\
\hline Gamma Scan & X-ray Radiography & Electronic real-time radiography. \\
\hline
\end{tabular}




\section{RESOURCE NEEDS FOR SFFF DURING CONSTRUCTION AND OPERATION}

It is assumed that none of the existing building will be used to facilitate the SFFF operation. The new facility will be built. A three to five year construction schedule is assumed for building the SFFF and approximately two years for the cold and hot startup. It is normal that during initial cold startup some minor construction work, as well quality assurance activities, need to be completed.

The values estimated below are based on Surplus Plutonium Disposition Environmental Impact Statements and MOX Fuel Fabrication Facility Environmental Impact Statements for Savannah River Site and Pantex Plant.

\subsection{Electrical Use}

Pantex Plant estimated $750 \mathrm{MWh}$ annual demand and 2,250 MWh total during three years construction period for 120,000 sqft fuel fabrication facility for an annual out put of 105 MT HM. O'Connor (1998a) estimated 2,800 MWh total during 3-yr construction period. The SFFF facility capacity (annual through put) is closer to ORNL proposed MOX facility. Therefore, average annual, total, and peak demand is assumed to be $750 \mathrm{MWh} / \mathrm{yr}, 2,800 \mathrm{MWh}$ and $1 \mathrm{MWe}$, respectively, same as estimated by O’Connor (1998a).

Depending on site selection, diesel generators may be required. If the selected site has electrical power available, no diesel generator will be needed.

During normal operation, electricity needs vary significantly depending on the overall process; 12,000 MWh for $100 \mathrm{MT}$ HM/yr Pantex Plant to 24,000 MWh for $200 \mathrm{MT}$ HM/yr Westinghouse estimate for recycle fuel plant. The ORNL for lead test assemblies estimated annual electricity demand of 180 MWh for 2.1 MT HM/yr processing (O’Connor 19998a, 1998b). The SFFF process is similar to Pantex and ORNL proposed MOX Plant. Based on the average of the two plants, the annual electricity requirement will be approximately $105 \mathrm{MWh} / \mathrm{MT}$. The SFFF will process less than $10 \mathrm{MT} \mathrm{HM} / \mathrm{yr}$. Therefore, the annual electricity requirement would be 1,050 MWh/yr. However, Pantex and ORNL proposed MOX facilities assumed that plutonium oxide would be received at the processing plant. (The thermally-induced gallium removal process (TIGR) is an energy intensive process and assumed to require the same energy at front end for Pu reprocessing as much as fuel fabrication. Most utility need will be for processing. The base load is expected to be small compare to processing load. Based on the linear scaling, annual electricity need of $\sim 2,100(2 * 1,050) \mathrm{MWh}$ is estimated. Assuming $100 \%$ contingency factor, peak electrical demand is estimated to be $\sim 2 \mathrm{MW}$ during operation.)

\subsection{Fuel}

The need for diesel generator during construction will depend on the site selection. The fuel consumption for new MOX FFF at the Pantex plant during construction is estimated to be $60,200 \mathrm{gal} / \mathrm{yr}$. ORNL estimated total 12,000 gallons of fuel need during construction. Proposed Pantex Plant facility is a new construction. ORNL has proposed the modification of existing facility. The SFFF will be approximately half the size (sqft) compared to Pantex plant. Using a linear scaling and adding the $30 \%$ contingency, the fuel requirement during the construction is estimated to be $40,000 \mathrm{gal} / \mathrm{yr}$. 
The SFFF will be designed to meet NRC license requirement. O'connor (1998a) estimated based on total $150 \mathrm{~kW}$ capacity two diesel generators, the fuel requirement of $1,260 \mathrm{gal} / \mathrm{yr}(4,600 \mathrm{l} / \mathrm{yr})$. A total $30 \mathrm{~h} / \mathrm{yr}$ testing time based on 2 diesel generators, $1 \mathrm{hr} / \mathrm{mo}$ testing, 12 times a year was assumed. During normal operation, the estimated peak demand for SFFF is estimated to be $1 \mathrm{MW}$. Assuming 50\% capacity is needed for safe shutdown and standby, the fuel requirement will be 4,100 gals/yr.

\subsection{Natural Gas}

Assuming $325 \mathrm{scf}$ of natural gas per square foot per year for heating, $1 \times 10^{6} \mathrm{yd}^{3}$ of per year will be needed.

\subsection{Concrete}

The SFFF will be approximately half the size (sqft) of the Pantex palnt. Badwan (1998) estimated $13,400 \mathrm{yd}^{3}$ of concrete for the new Pantex plant. Using a linear scaling and adding the $30 \%$ contingency, the concrete requirement during construction is estimated to be $8,700 \mathrm{yd}^{3}$.

\subsection{Water}

During construction, the dominant water use will be to satisfy personnel need and concrete mixing. O'Connor (1998a) estimated $4 \times 10^{6}$ gallons of water requirement during construction. Using a linear scaling and adding the $30 \%$ contingency, water requirement during construction is estimated to be $3 \times 10^{6}$ gallons.

\subsection{Steel}

The carbon steel required for construction include the amounts needed for reinforcing steel, structural steel, and steel siding. Badwan (1998a) assumed the steel volume to be $4 \%$ of the concrete volume. Therefore, the steel requirement would be 2,600 tons.

\subsection{Employment ${ }^{\mathrm{a}}$}

The construction employment during the proposed modification of existing facility at SRS is estimated to be 122 total workers per shift and 2 shifts per day over two years. The proposed SFFF plant will be a new construction and will require more effort. It is assumed it will take three to five years, $50 \%$ extra effort, to build a new facility. Assuming 100\% contingency, 250 worker-years are estimated. Based on the $50 \%$ increase in employment during peak construction period, peak employment would be 120 workers.

The SRS (O'Connor 1998a) and LLNL (O'Connor 1998b) estimated 60 to 72 worker-shift/day during normal operation. Since, the SFFF operation and capacity is very similar, the annual employment would be the same. However, pre-conditioning of WG plutonium, thermally induced gallium removal process, which is not included in SRS or LLNL MOX FFF dsign, will be done at the SFFF. To account for additional processing, total employment is increased by $15 \%$. Total staffing is estimated to be 83 and assume $65(80 \%)$ of them would be rad-workers.

\footnotetext{
${ }^{a} 250 \mathrm{~d} / \mathrm{yr}$ is assumed.
} 


\subsection{Construction Area}

Pantex MOX project (Badwan 1998) assumed 5 acres laydown area. Since SFFF is not significantly different in physical size, same size of laydown area, 5 acres, and parking lot area, 5 acres, is assumed.

\subsection{Nuclear Fuel inventories}

The facility will be designed to manufacture 120 assemblies per year. In the case of oxide or metal fuel, total throughput of $\mathrm{Pu}$ is estimated to be $1.4 \mathrm{MT}$ per year. The total throughput of depleted uranium (DU) is estimated to be 3.63 and 5.08 MT for oxide and metal fuel, respectively. It is assumed that no more than $4 \mathrm{~kg}$ of $\mathrm{Pu}$ will be used per batch due to criticality concern. A $4 \mathrm{~kg} \mathrm{Pu}$ feed rate will result in a maximum of less than $7 \mathrm{~kg}$ of $\mathrm{Pu}$ in the process at any time. Figures 6 and 7 show the plutonium mass balance for the metal and MOX fuel processes, respectively.

Most of the plutonium inventories will be in the form of fuel assemblies and feedstock. To minimize Pu inventory at the site, two shipments of fuel assemblies per year and two shipments of feed stock per year are assumed. This results in the total Pu inventory of at the site being 1.5 MT in the SFFF. Assuming 50\% contingency, the total Pu inventory in the SFFF would be $2.2 \mathrm{MT}$.

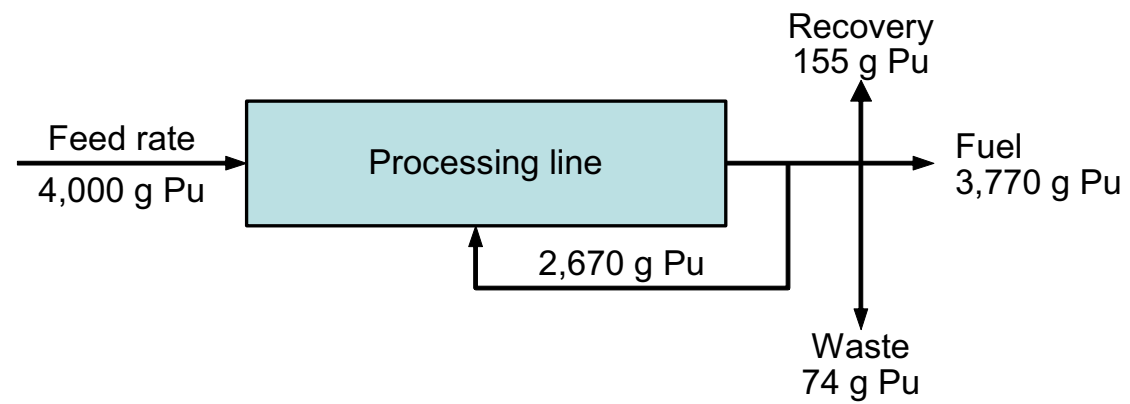

Figure 6. Plutonium inventory in metal fuel processing line.

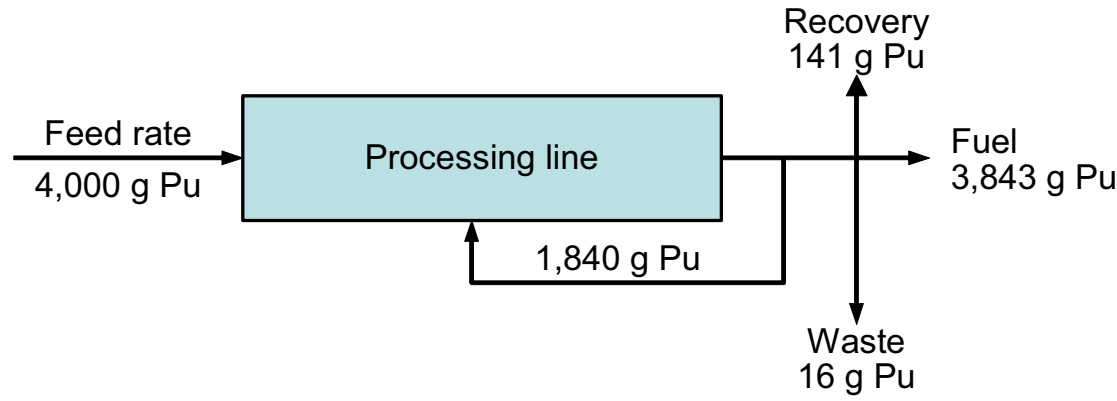

Figure 7. Plutonium inventory in MOX fuel processing line.

\subsection{Air Pollutant}

Pantex plant project estimated $13 \mathrm{MT} / \mathrm{yr}$ pollutant and $<0.2 \mathrm{MT} / \mathrm{yr}$ hazardous pollutant to process 3.3 MT/yr plutonium and MOX fuel. Based on these estimates, the air pollutant and hazardous pollutant for SFFF is estimated to be $5 \mathrm{MT}$ and $<0.1 \mathrm{M}$, respectively. 
Table 2. Estimated Resource needs and waste generation during construction

\begin{tabular}{|c|c|}
\hline \multicolumn{2}{|c|}{ CONSTRUCTION PHASE } \\
\hline Peak Electrical Energy & $100 \mathrm{~kW}$ (average $140 \mathrm{MWh}$ annual) \\
\hline Diesel Generators & Yes, (Average $40,000 \mathrm{gal} / \mathrm{yr}$ ) \\
\hline Concrete $\left(\mathrm{yd}^{3}\right)$ & 8,700 \\
\hline Steel (t) & $500-2,600^{b}$ \\
\hline Water (gal) & $3 \times 10^{6}$ \\
\hline \multicolumn{2}{|l|}{ Land (acre) } \\
\hline Laydown Area Size & 48 \\
\hline Parking Lot & 5 \\
\hline \multicolumn{2}{|l|}{ Total Employment } \\
\hline Total Employment (Worker Years) & 250 \\
\hline Peak Employment (Workers) & 120 \\
\hline Construction Period (years) & 3 \\
\hline Waste Generated & Volume \\
\hline Low level & $\begin{array}{l}\text { NA - None unless selected site has been identified } \\
\text { as contaminated. }\end{array}$ \\
\hline Mixed-low Level & $\begin{array}{l}\text { NA - None unless selected site has been identified } \\
\text { as contaminated. }\end{array}$ \\
\hline \multicolumn{2}{|l|}{ Hazardous } \\
\hline Liquid (paints, oil, etc.) (gal) & 1400 \\
\hline Solid $\left(\mathrm{yd}^{3}\right)$ & $3-5$ \\
\hline \multicolumn{2}{|l|}{ Non-Hazardous (Sanitary) } \\
\hline Liquid (gal) & 420,000 \\
\hline Solid $\left(\mathrm{yd}^{3}\right)$ & 120 \\
\hline \multicolumn{2}{|l|}{ Non-hardous (other) } \\
\hline Liquid (gal) & NA \\
\hline Solid $\left(\mathrm{yd}^{3}\right)$ & 50 \\
\hline
\end{tabular}

\footnotetext{
${ }^{\mathrm{b}}$ Depends on new construction or remodeling of existing facility.
} 
Table 3. Estimated Resource needs and waste generation during operation

\begin{tabular}{|c|c|}
\hline \multicolumn{2}{|l|}{ ANNUAL OPERATION } \\
\hline Annual Electrical Energy (MW-h) & 2100 \\
\hline Peak Electrical Energy (MW (e)) & 2 \\
\hline Fuel Usage (gal) & 4100 \\
\hline Heating Gas $\left(\mathrm{yd}^{3}\right)$ & $1 \times 10^{6}$ \\
\hline Other Process Gas $\left(\mathrm{N}_{2}, \mathrm{Ar}\right.$, etc) & $\mathrm{F}, \mathrm{H}_{2}, \mathrm{Ar}, \mathrm{N}_{2}, \mathrm{Ga}_{2} \mathrm{O}, \mathrm{NOx}, \mathrm{CO}_{\mathrm{x}}$ \\
\hline Water (gal) & 703,400 \\
\hline Steam (tons) & NA \\
\hline Plant Footprint (acres) & $2($ PLANT) \\
\hline & 5 (PARKING) \\
\hline Employment & 83 (TOTAL) \\
\hline Number of Rad Workers & 65 \\
\hline Average Annual Dose & $0.01 \mathrm{Rem} / \mathrm{yr}$ \\
\hline Maximum worker Dose & $0.04 \mathrm{Rem} / \mathrm{yr}$ \\
\hline Radionuclide emissions and effluents - nuclides and curies & $0.3 \mathrm{mg} / \mathrm{Pu}$ \\
\hline & 70 micro $\mathrm{Ci} / \mathrm{yr}$ \\
\hline NAAQS Emissions (tons/yr) & $4-6$ \\
\hline Hazardous Air Pollutants and Effluents (tons/yr) & $<0.1$ \\
\hline Chemical Use & See Attached List \\
\hline Maximum inventory of fissile material/through put & Max 1.5 core $/ 0.5$ core \\
\hline Waste Generated & Volume \\
\hline Low level & \\
\hline Liquid (gal) & 150,000 \\
\hline Solid $\left(\mathrm{yd}^{3}\right)$ & 52 \\
\hline Mixed-low Level & \\
\hline Liquid (gal) & $<1$ \\
\hline Solid $\left(\mathrm{yd}^{3}\right)$ & Minute \\
\hline TRU & \\
\hline Liquid (gal) & 344 \\
\hline Solid $\left(\mathrm{yd}^{3}\right)$ & 52 \\
\hline
\end{tabular}




\begin{tabular}{|l|l|}
\hline HLW/SPENT FUEL & None \\
\hline Hazardous & \\
Liquid (gal) & 60 \\
Solid (yd $\left.{ }^{3}\right)$ & 0.75 \\
\hline Non-Hazardous (Sanitary) & \\
Liquid (gal) & $2.2 \times 10^{6}$ \\
Solid (yd $\left.{ }^{3}\right)$ & 2,043 \\
\hline Non-hardous (other) & \\
Liquid (gal) & 35 \\
Solid (yd $\left.{ }^{3}\right)$ & $130-150$ \\
\hline
\end{tabular}

Table 4. List of annual chemical consumption for operations*

\begin{tabular}{|l|l|l|}
\hline \multicolumn{1}{|c|}{ Chemical } & Reference value & Estimated \\
\hline Liquids, gal & & \\
\hline Alcohol & 60 & 140 \\
\hline General Cleaning Fluid & 60 & 60 \\
\hline Solvent (30 vol \% tri-butyl phosphate in paraffin hydrocarbon) & 4 & 2 \\
\hline Hydrofluoric acid & 24 & 10 \\
\hline Formic acid & 21,500 & 9,300 \\
\hline Gases, scf & & \\
\hline Argon, M & & $1.7 \times 10^{6}$ \\
\hline Helium (process gas) & 56,800 & 800 \\
\hline Hydrogen (for MOX sintering furnace) & 350 & 85,500 \\
\hline Oxygen (MOX dry recycle process) & 35,000 & 41,000 \\
\hline Nitrogen (Glove boxes) & 18,000 & 440,000 \\
\hline Nitric oxide & 19,000 & 13,000 \\
\hline Solids, lb & 30,000 & \\
\hline Hydroxylamine nitrate & & 660 \\
\hline Aluminum nitrate nanohydrate & 1500 & 1200 \\
\hline Oxalic acid dehydrate & 2700 & 6,600 \\
\hline Reillex HPQ resin (wet) & 15,000 & 150 \\
\hline Nitric acid (laboratory), lb & 360 & 5 \\
\hline Hydraulic Fluid (lubricant), lb & 2 & 10 \\
\hline Hydrochloric acid (Laboratory), lb & 10 & \\
\hline & 1 & \\
\hline
\end{tabular}




\begin{tabular}{|l|l|l|}
\hline Polyethylene glycol (MOX blending process), lb & 45 & 45 \\
\hline Sodium hydroxide (Laboratory), lb & 34 & 34 \\
\hline Sodium nitrate(Laboratory), lb & 200 & 200 \\
\hline Sulfuric acid (laboratory), lb & 5 & 5 \\
\hline Zinc stearate (MOX pellet pressing process), lb & 45 & 105 \\
\hline$*$ These numbers are scaled based on total throughput in SRS MOX fuel lead assembly or Pantex data report. \\
\hline
\end{tabular}

\subsection{Transportation}

A Safe-Secured Trailer (SST) can accommodate 30-35 packages per trailer. A single SST convoy can deliver three trailers; total of 100 packages. Each package can carry a maximum of $4.4 \mathrm{~kg}$ of plutonium. Based on $440 \mathrm{~kg}$ of plutonium per convoy, a total of six convoys would be required. Assuming two shipments per year, three convoys per shipment would be needed.

Depleted uranium can be shipped in standard drums. Table 5 lists the specific data on plutonium and depleted uranium transport.

Table 5. Transportation of $\mathrm{Pu}$ and DU to the SFFF

\begin{tabular}{|c|c|}
\hline \multicolumn{2}{|c|}{ Transportation of $\mathrm{Pu}$} \\
\hline $\begin{array}{l}\text { Number of shipment to the SFFF } \\
\text { Container Types used for shipment } \\
\text { Availability of containers } \\
\quad \text { Likely candidate package are } 9975 \\
\quad \text { (DOE-9975) or perhaps SAFKEG (3940A) } \\
\text { Average Shipping container weight, kg } \\
\text { Average material loaded into container, kg } \\
\text { Average isotopic contents }\end{array}$ & $\begin{array}{l}2 \text { per year; } 3 \mathrm{SST} \text { s convoy/shipment; } 3 \\
\text { trailers/Convoy } \\
\text { Type B } \\
\text { May require new certificate or modification } \\
\text { of existing certificate for site specific } \\
\text { application. Need to evaluate for National } \\
\text { security requirements. } \\
130 \text { to } 181 \mathrm{~kg} \\
4.4 \text { to } 4.5 \mathrm{~kg} \\
\text { Typical WG Pu }\end{array}$ \\
\hline \multicolumn{2}{|c|}{ Transportation of depleted uranium } \\
\hline $\begin{array}{l}\text { Number of shipment to the SFFF } \\
\text { Approximately } 24 \text { drums would be needed, } \\
\text { each containing } 250 \mathrm{~kg} \text { DU } \\
\text { Container Types used for shipment } \\
\text { UN1A2 steel } 55 \text { gallons drum } \\
\text { Availability of containers } \\
\text { Average Shipping container weight, } \mathrm{kg} \\
\text { Average material loaded into container, } \mathrm{kg} \\
\text { Average isotopic contents }\end{array}$ & $\begin{array}{l}2 \text { per year; maximum } 3 \text { MT per shipment } \\
55 \text { gallons drum } \\
\text { Yes } \\
275 \mathrm{~kg} \\
250 \mathrm{~kg} \\
\text { Typical depleted uranium }\end{array}$ \\
\hline
\end{tabular}




\section{REFERENCES}

1. Badwan, F. (1998), et al., Data Call for a Mixed Oxide Fuel Fabrication Facility Located at the Pantex Plant, LA-UR-97-2067, Los Alamos National Laboratory, June 1998.

2. Bluhm, E. A. (2004), 'Pu02 Polishing for MOX Fuel Fabrication-Process Modifications and Upgrades', LA-UR-04-3749, (Submitted to 28th Annual Actinide Separations Conference Asheville, NC), Los Alamos National Laboratory, June 2004.

3. DeMuth, S. (1997), 'Conceptual Design for Separation of Plutonium and Gallium by Solvent by Solvent Extraction', LA-UR-97-181, Los Alamos National Laboratory, April 1997.

4. DOE-9975, U. S. Department of Energy, Certificate of Compliance for Radioactive Material Packages - USA/9975/B(M)F-85 (DOE)

5. Hodge, S. A. (2006), and L. J. Ott, Implications of the PIE Results for the 50-GWd/MT MOX Test Capsules, ORNL/TM-2006/83, UT-Battelle, LLC, Oak Ridge National Laboratory, May 2006.

6. Kolman D. G. (200), M. E. Griego, C. A. James, and D. P. Butt, "Thermally induced gallium removal from plutonium dioxide for MOX fuel production" Journal of Nuclear Materials 282 (2000) $245 \pm 254,(2000)$.

7. O’Connor, D. G. (1998a), et al., "SRS MOX Fuel Lead Assemblies Data Report for the Surplus Plutonium Disposition Environmental Impact Statement", ORNL/TM-13483 Oak Ridge National Laboratory, August 1998.

8. O’Connor, D. G. (1998b), et al., 'LLNL MOX Fuel lead Assemblies Data Report for the Surplus Plutonium Disposition Environmental Impact Statement', ORNL/TM-13480 Oak Ridge National Laboratory, August 1998.

9. ORNL 1998, 'Technical Report for Generic Site Add-On Facility for Plutonium Polishing Fissile Materials Disposition Program' ORNL/TM-13662, Oak Ridge National Laboratory, June 1998.

10. Ott, L. J. (2005), S. A. Hodge, and R. N. Morris, Weapons-Derived Mixed Oxide Fuel Test Irradiation Summary, ORNL/TM-2005/255, UT-Battelle, LLC, Oak Ridge National Laboratory, December 2005.

11. Sanzo, D. (2006), R. Erickson, J. Ireland, "Initial Assessment of Plutonium Feeds Available for Global Nuclear Energy Partnership (GNEP) Activities”, LA-UR-06-7975, Los Alamos National Laboratory, July 2006.

12. Wilson, D. F., et al. "Interaction of Zircaloy Cladding with Gallium 1997 Status", ORNL/TM13505, November 1997. 